\title{
The Demand for Children in a "Natural Fertility" Population
}

\author{
DENNIS DE TRAY*
}

The paper is concerned with two theories that proport to explain fertility variations in developing countries. The first of these theories is based on supply or natural fertility considerations while the second looks to (the underlying) costs and benefits of children as one source explanation for fertility differences. These theories indicate that demand consideration do explain some of the systematic variation in fertility even among "noncontracepting" populations.

Knowledge of factors that influence fertility levels and, therefore population growth rates is a vital input into a variety of policy decisions in developing nations. At this time, there is only limited information on what it is about couples' environments, backgrounds, and personal characteristics that result in their having many or few children, but among the competing theories, two have emerged as leading contenders - the supply or natural fertility theories, and the demand or choice theories.

These two theories lead to substantially different recommendations with respect to policies aimed at lowering population growth rates. Efficient resource allocation would, therefore, be well served if there were some evidence on which of these theories best fits the fertility behaviour of couples in low income and developing nations. The research presented below is an attempt to supply this evidence for one important empirical relationship observed in most developing countries - the negative partial correlation between a wife's schooling and the number of children she has.

\section{THE COMPETING THEORIES 1}

Natural fertility is, in the words of its most famous proponent, "the fertility of a population that makes no deliberate attempt to limit births"

*The Rand Corporation. At the time this paper was written, the author was Research Advisor with the Pakistan Institute of Development Economics, and Associate with the Population Council. He would like to thank Dick Goldman, Khalil Hamdani, Jeff Hammer, Harvey Leibenstein, David Oot, and Warren Robinson for comments on an earlier draft.

"When the merits of alternative theories are debated, "truth" almost invariably lies between the two extreme positions being taken, and such is surely the case here. For the sake of simplicity and argument, however, I will treat the demand and supply explanations for variations in fertility as mutually exclusive. 
$[8$, p. 2]. Since natural fertility is "primarily a biological phenomenon" (ibid.), it follows that in populations exhibiting this characteristic, desires for children play no role in determining family resource allocation, with completed fertility the (perhaps unintended) consequence of decisions made in other spheres of family behaviour. While one might debate why such an important element in a couple's life as children would be relegated to the category of residual claimant in the household decision-making calculus, the concept of natural fertility has been popular among demographers and social scientists, especially as a means of describing demographic outcomes in traditional and developing societies.

Henry, in his seminal article on natural fertility [8], indicated that populations will seldom be observed in a state of "true" natural fertility, but modern proponents of this concept have broadened it to include populations in which there is no observable attempt to avoid pregnancy for the sake of limiting family size [7], and/or where couples are vague or unconcerned about such concepts as desired family size and "ideal" numbers of children. Accordingly, one potential indicator of a society which is in or near a natural fertility state is whether couples in that society use or demand some form of modern contraception. If there is no use of modern contraception even in the face of adequate supplies of contraception, it may be argued that parents have no desire to restrict their family size beyond the limits imposed by the biological processes involved in conception and birth. ${ }^{2}$

In a natural fertility population, policies aimed at reducing population growth rates are likely to fall into one of two categories - those aimed at "educating" couples both about the benefits of small families, and about the means of limiting family size (modern contraception, in particular), and those aimed at increasing the availability and acceptability of different forms of contraception (family planning programmes, for example). Casual observation would suggest that the majority of population-oriented policies in developing nations, and certainly those in Pakistan, fall into one or both of these categories and are, in that sense, based on the presumption of a natural fertility population.

The demand theory, in its most general form, postulates that children are but one among many potential avenues through which couples can spend their wealth. If that is the case, fertility decisions should be viewed in the same light as any other consumption decision that couples make over their lifetime. ${ }^{3}$ In fact, it could be argued that given the sizable proportion of a couple's resources that go toward having and rearing children, desires for children could well dominate many other areas in which families make decisions.

The main premise of the demand theory of family size is that children are not showered on parents in some uncontrolled fashion, but are, rather, the outcomes of implicit or explicit decision-making by parents. This theoretical

"If the reader is uncomfortable with the use of "natural fertility" to describe a Population in this state, and would prefer some other term, so be it. This paper is not at all concerned

with usefulness of the concept, or exact definition of the term, natural fertility.
${ }^{3}$ For specific examples of this theory, see $[3,4,12]$ and especially [14]. framework is based on the assumption that many of the factors that bear on parental decisions to purchase consumption items from the marketplace (food, consumer durables, and so on) should also affect the "purchase" or production of children. Among the more important of these factors are the price that parents have to pay in order to have and raise another child, and the amount of resources that parents have at their disposal, that is, family income or wealth. If children are like other items consumed by households, then, as the cost of producing children rises, holding family wealth or income constant, the number of children desired and produced by parents will decline. Conversely if the cost of children remains unchanged but family income rises, then parents will want to consume (produce) more children as long as children are normal goods in the economic sense of the term.

This theory is receiving growing acceptance as an explanation of fertility differences in countries in which a substantial proportion of the married population uses or has used some form of modern contraception; it is, however, often viewed with considerable scepticism in the context of traditional and developing societies. ${ }^{4}$ The gist of the criticism levelled at the use of these models to understand fertility behaviour of, say, rural villagers in Pakistan is that couples in that environment do not think rationally or even consciously about the number of children they want. Partly this is a "proof of the pudding is in the eating"' issue-whether the theory is useful in studying fertility in developing nations depends on whether it provides a framework or language that helps us to understand better some of the regularities observed in the behaviour of families and individuals living in those countries. This is an empirical question not resolvable by debating the merits of the theory.

And partly, the issue centres on what one means by rationality and conscious decision-making. The important question with respect to demand theories is: If people appear to have no conscious, or at least only very weak preference for a particular number of children, can the demand theory be rejected out of hand? If the answer to this question is no, then the only means of determining which theory-demand or supply-is valid is through empirical testing.

In this regard, consider the following argument. It is often said of low income and developing societies that tradition and culture dominate many of the important decisions individuals make over their lifetimes. For example, couples are thought to have many children because community or societal norms dictate the acceptability of large families. But how do norms or traditions come about? If it could be argued that norms in the area of, say, family size, were originally based on the sorts of considerations that underlie the demand model, then the fact that individuals do not undertake an elaborate choice calculus with regard to the numbers of children they have would in no way negate the usefulness of demand-oriented theories of fertility. 
But, if norms are "rational" in the sense that they conform to the predictions of the demand model, who originally went through the calculations necessary to derive these behavioural guides? The answer may well be no one person but society as a whole, with the process looking something like the following: At any point in time, and over time, each family carries out an experiment in resource allocation for the community in which it lives. These experiment in resource level of behaviour based on the experience of past generations (norms) and resulting outcomes, and, for certain perience of past generations (norms) and resulting outcomes, and, for certain families, a random element both unexpected and outside the control of the couples in question. This random element in couples' lives supplies the community with information on the relative costs and benefit of different life styles for people of similar social and economic backgrounds; that is, it supplies information on the wellbeing of people who, for reasons unassociated with their own desires, stray off the beaten path in one or another area of family behaviour.

As an example, a community will be able to observe the costs and benefits associated with small versus large families simply through the varying levels of fecundity in the population. Some couples will have fewer children than other couples with like social and economic characteristics because the wife is, for innate biological reasons, subfecund. Over the course of time, the community at large will be able to observe how well off, happy, rich, etc. these couples are relative to couples with average fertility levels, and thus will know almost instinctively whether, ceteris paribus, they should strive for lower fertility. ${ }^{5}$ If subfecund couples tend on average to be worse off in terms of whatever welfare measures the community deems important, then future generations will do what they can to promote high fertility. Again, the community will learn of ways to promote high fertility by "observing" families whose life styles lead them to have above-average numbers of children.

The point of the preceding discussion is not to suggest that this is necessarily the way things are, but rather to argue that there are processes that can lead to individual "rationality" in behaviour that do not involve complex costbenefit analyses or even a great deal of conscious choice at a particular point, in time. Thus, to say that people do not plan their fertility, or are vague about the number of children they want is not, in and of itself, a refutation of demand models of fertility.

\section{AN EMPIRICAL TEST}

If we cannot dismiss on a priori grounds the demand side of the fertility equation in traditional societies, are there empirical tests which might distinguish between the demand and the supply models? As will be seen, the difficulty lies in deriving hypotheses from the two theories which result in different culty lies in deriving the fecundity vary within as well as among social and economic groups,

${ }^{\circ}$ Fertility-reducing or increasing life styles do not necessarily correspond to concepts of modern versus traditional fami'ies that is, the argument given in the text should not be taken as support f r "modernizing" theories of fertility decline. predictions for the relationship between actual fertility behaviour and other observable characteristics of couples. The stress here is on "observable" since many of the conceptual variables in both theories are difficult to measure directly and thus are not available in most data sets. For the demand theory, some examples are the opportunity costs (value) of the wife's time, the price of children, and the family's real wealth; and for the supply models, "natural" fecundity, actual rather than stated contraceptive use, and desired family size. It is, in fact, the use of proxies to measure some of these variables that has allowed proponents of demand and proponents of supply theories to take the same set of statistics on a population and for each to claim victory for his elsewhere particular perspective.

As an illustration of this phenomenon, consider the regression given in Table 1 which is drawn from some earlier work on socio-economic determinants of fertility in Pakistan [5]. The sample for this regression was drawn from Pakistan's National Impact Survey (NIS) conducted in 1968-1969, and consists of women between the ages of 35 and 49, who were married at the time of this survey. ${ }^{7}$ The variables and their construction are discussed in detail [5]; definitions are given in the Appendix.

As the table indicates, the proxies used to measure the family's wealth position are the husband's education, and some characteristics of the house in which the family resides. If one accepts this interpretation, then the demandtheory hypothesis that wealthier families have more children is supported by virtually every wealth proxy. The major price-related proxy is the education level of the wife, and again, under this interpretation the demand argument that an increase in the opportunity cost of a wife's time leads to lower fertility is supported. ${ }^{8}$ And, finally, the unimportance of the other variables in the regression (with the exception of the family's mortality experience) can be taken as an indication that in Pakistan cultural differences in couples' backgrounds play no role in influencing fertility after one controls for differences in individual characteristics in the population.

Can this regression be taken as validation, at least for Pakistan, of demand theories of fertility? Proponents of supply-oriented explanations for variations in fertility would argue that it cannot be on the grounds that each coefficient in Table 1 can be explained purely on the basis of supply considerations. ${ }^{2}$ One frequently-cited example is the negative effect of wife's education

${ }^{7}$ The lower end of the age range is designed to restrict the sample to women who have completed or nearly completed their fertile period. The upper end is a survey-imposed completed or neaximum age.
max

${ }^{8}$ The use of schooling as a proxy for the value of wife's time for Pakistani women receives strong support from a forthcoming study wage rates for women who choose to work. 'Citing sources of the supply explanations given in the text is not an easy matter since many have yet to be set down in the literature. One exception is [7]. The sources of many explanations of fertility that have taken place in conferences and private conversations over the past several years. Of particular importance are the recent IUSSP workshop on Household Models of Economic-Demographic Decision-making in Developing Countries held in Mexico City in November 1976, and private conversation with Richard Easterlin of Pennsylvania
University, and John Bongaarts of the Population Council. 
Table 1

Dependent Variables: Completed Fertility, All Women Ages 35 to 49

Coefficient t-Ratio

\section{Wealth Proxies}

0.38

$-0.09$

0.66

0.64

0.23
2.0

2.1

Price Proxies

$$
\begin{aligned}
& \text { 6. Wife's education } \\
& \text { 7. Rural } 1
\end{aligned}
$$

8. Rural 2

Wife's Background Variables

$$
\begin{aligned}
& \text { 9. Born village } \\
& \text { 10. Lived in town } \\
& \text { 11. Current age }
\end{aligned}
$$

Other Variables
12. Mortality
13. Intercept
2.74

$$
\mathrm{N}=861 ; \mathrm{R}^{2}=0.10 ; \quad \mathrm{F}=7.62
$$

Source: [5, p. 96].

Note: See Appendix for definition of variables.

Data Base: The 1967-68 National Impact Survey (Pakistan).

on the number of children ever born to her. Demand theorists treat female education as a price variable, and take the negative sign of its coefficient as an indication that demand curves for children are downward sloping. In contrast, supply proponents argue that the negative wife's education coefficient results not from behavioural responses to changes in the price of children, but from the fact that more education implies, on average, higher age at marriage, and higher education levels of contraceptive knowledge and contraceptive use. Thus, female education "reduces" fertility because (1) it shortens the period over which women are at risk of becoming pregnant; and (2) it acts as a proxy for separating those couples who are truly at natural fertility levels from those trying to reduce their fertility to levels below natural fertility rates. In this explanation, behaviour, in the sense of a response to changing relative prices, does not enter the picture.
The Impact data on which this regression is based allow us to determine at least tentatively which of these competing explanations is more likely to be true. First, the data give for each married woman the age at which she married, so we can control for duration of marriage by including in the regression age at marriage along with the wife's current age; second, we can eliminate the role played by modern contraception by stratifying the sample into those who have ever used and those who have never used any form of modern contraception ${ }^{10}$ (the NIS contains detailed information on current and past contraceptive use).

It is important to note that, econometrically, neither of these "controls" may be legitimate because both age at marriage and contraceptive use are likely to be influenced by a couple's desires for children; that is, the causal relationship between these variables and fertility may not be unidirectional. When a jointlydetermined or endogenous variable is treated as an exogenous variable, as is the case in the following empirical work, we run the risk of introducing simultaneity bias into the analysis. Because of this potential bias, the tests described below must be viewed as tentative.

Differences between the contracepting and noncontracepting populations of Pakistan are well illustrated by a simple comparison of the mean characteristics of the two groups. These comparisons are given in Table 2 in which the sample used for the regression in Table 1 is stratified along ever used/never used lines. The most striking comparison is that for a number of children ever born for the two groups - contraceptors had on average 1.1 more children ever born than those who said that they had never used any form of modern contraception. This is true even though duration of marriage is approximately the same for the two groups, and female education levels are substantially higher for ever-used than for never-used women. Further, mortality levels among the children of those couples who have never used contraceptives are on the other of 40 percent higher than mortality levels among users' children. This means that for women between 35 and 49 in 1968-1969, those who had ever used contraceptives had on average 28 percent more living children than those couples who had never used modern contraceptives.

While several interpretations can be attached to these comparisons, I suggest that one strong possibility is that much contraceptive use in Pakistan during the period covered by the Impact Survey was demand determined. Put another way, it was those couples who found themselves with unexpectedly high numbers of children ever born and living children who sought out and used modern forms of contraception. This interpretation receives further support if we look not at actual fertility, but at the fertility levels which couples in the two groups could have expected based on their own characteristics and the average fertility of couples like them (i.e., with the same socio-economic characteristics). Expected fertility can be approximated using the estimated coefficients 
in Table 1, and the average characteristics for the two groups given in Table $2 .{ }^{11}$ For nonusers, expected fertility based on the preceding calculation is 6.61 children per couple, which is very close to the actual average fertility for that group (6.60 children ever born). However, for those who have ever used any form of modern contraception, expected fertility is 6.43 children ever born which implies that on average these couples had 1.3 (7.71-6.43) more live births than other couples in the population with similar social and economic characteristics.

Thus, it appears that fertility in excess of the already high mean fertility levels in Pakistan induces couples to search out and use modern forms of contraception. Although not central to the purpose of this paper, it is worth noting that almost all family planning programmes, including Pakistan's, are based on the premise that supply and availability of contraceptives are the factors explaining variations in contraceptive use. While the foregoing analysis does not rule this out as a partial explanation, it does confirm that desires for specific numbers of children also are important in influencing couples' contraceptive behaviour; in fact, for Pakistan, these demand factors appear to dominate contraceptive choice decisions. The figures in Table 2 also suggest that excess or unwanted fertility occurs only at very high levels of children ever born, and therefore that programmes aimed at reducing population growth rates must both eliminate unwanted births, and reduce the number of wanted or desired births.

The question that remains is whether within the noncontracepting or natural fertility population there is any evidence that demand factors are at work. To answer this question, the regression given in Table 1 was recomputed using as the base sample only those 753 women who said that they had never used any form of modern contraception. This regression is given as equation 2 in Table 3. Equation 3 in that table adds to the original specification the age at which each woman was first married, thus introducing into the regression a control for duration of marriage. The first equation in Table 3 reproduces for ease of comparison the regression given in Table 1 .

The change in samples from all women to those who have never used modern contraception is an attempt to rule out the correlation between female education and contraception as the explanation for the negative partial correlation between wife's schooling and fertility. As Table 3 indicates, dropping women who have "ever used" from the sample makes the coefficient on wife's education more negative and its t-ratio increases; supply explanations based on the education/contraception correlation would have predicted a movement in the opposite direction for both these magnitudes.

To determine whether female education is acting as a proxy for "exposure", that is, for the length of time over which women have been at risk of becoming pregnant, equation 3 repeats equation 2 but with the addition of

11Should any one choose to check these calculations it must be kept in mind that the mean
of husband's education squared is not the square of mean husband's education; the value of husband's education squared is not the square of mean husband's education; the
correct averages for husband's education squared are 5.42 for nonusers, and 9.28 for users.

Table 2

Ever Contracepted/Never Contracepted Comparisons ${ }^{\mathbf{2}}$

\begin{tabular}{lcc}
\hline & \multicolumn{2}{c}{ Means } \\
\cline { 2 - 3 } & $\begin{array}{c}\text { Nonusers } \\
(\mathrm{N}=753)\end{array}$ & $\begin{array}{c}\text { Users } \\
(\mathrm{N}=108)\end{array}$ \\
\hline Children ever born & 6.60 & 7.71 \\
Husband's education & 1.38 & 2.22 \\
Electricity in house & 0.26 & 0.51 \\
Modern house type & 0.28 & 0.57 \\
Traditional house type & 0.58 & 0.34 \\
Wife's education & 0.23 & 0.83 \\
Rural 1 & 0.39 & 0.32 \\
Rural 2 & 0.22 & 0.08 \\
Wife born in village & 0.66 & 0.53 \\
Wife ever lived in town & 0.42 & 0.62 \\
Years married & 23.77 & 23.26 \\
Wife's current age & 40.02 & 38.96 \\
Age at marriage & 16.25 & 15.70 \\
Mortality & 0.25 & 0.18 \\
\hline
\end{tabular}
aContraceptors are those who have ever used any of the following forms of modern
contraceptives: condom, diaphragm, foam, jelly or cream, tampon or sponge, IUD, Pill, contraceptives: condom,
sterilization, abortion.

age at marriage as an explanatory variable. To reiterate, supply-based theories would predict that controlling for contraceptive use and duration of exposure ought to substantially reduce the negative partial correlation between female education and fertility. Equation 3 rather strongly rejects this explanation-the effect of wife's education on children ever born is essentially unchanged from equation 1 , both with regard to its absolute magnitude, and its significance level. ${ }^{12}$ It appears, then, that even within a "natural fertility" population, and controlling for duration of exposure, increases in female schooling still act as a negative influence on the number of children couples' want. Demand-based theories would predict this continued negative association; supply theories would not.

\section{SUMMARY AND CONCLUSIONS}

The preceding analysis is concerned with distinguishing between two competing theories that attempt to explain observed variations in fertility behaviour in developing societies. The first of these theories is based on supply considerations like fecundity, availability of contraceptives, post-partum

${ }^{12}$ The small decrease in the t-ratio can be explained by the change in degrees of freedom due to the reduction in sample size. 
Table 3

Regression Comparisons: All Women Versus Nonusers ${ }^{\mathrm{a}}$

Dependent Variable: Completed Fertility

\begin{tabular}{|c|c|c|c|}
\hline Explanatory Variables ${ }^{b}$ & $\begin{array}{l}\text { All Women } \\
(\mathrm{N}=861)\end{array}$ & & isers \\
\hline \multicolumn{4}{|l|}{ Wealth Proxies } \\
\hline 1. Husband's education & $\begin{array}{l}0.38 \\
(2.0)\end{array}$ & $\begin{array}{r}0.27 \\
(1.3)\end{array}$ & $\begin{array}{r}0.28 \\
(1.4)\end{array}$ \\
\hline 2. (Husband's education $)^{2}$ & $\begin{array}{c}-0.09 \\
(2.1)\end{array}$ & $\begin{array}{c}-0.06 \\
(1.3)\end{array}$ & $\begin{array}{r}-0.06 \\
(1.4)\end{array}$ \\
\hline 3. Electricity in house & $\begin{array}{l}0.66 \\
(2.6)\end{array}$ & $\begin{array}{r}0.71 \\
(2.7)\end{array}$ & $\begin{array}{l}0.71 \\
(2.7)\end{array}$ \\
\hline 4. Modern house type & $\begin{array}{l}0.64 \\
(2.1)\end{array}$ & $\begin{array}{r}0.45 \\
(1.4)\end{array}$ & $\begin{array}{r}0.52 \\
(1.7)\end{array}$ \\
\hline 5. Traditional house type & $\begin{array}{l}0.23 \\
(0.9)\end{array}$ & $\begin{array}{l}0.15 \\
(0.6)\end{array}$ & $\begin{array}{r}0.13 \\
(0.5)\end{array}$ \\
\hline \multicolumn{4}{|l|}{ Price Proxies } \\
\hline 6. Wife's education & $\begin{array}{r}-0.33 \\
(3.3)\end{array}$ & $\begin{array}{c}-0.42 \\
(3.7)\end{array}$ & $\begin{array}{c}-0.35 \\
(3.1)\end{array}$ \\
\hline 7. Rural 1 & $\begin{array}{r}0.10 \\
(0.3)\end{array}$ & $\begin{array}{c}0.32 \\
(0.83)\end{array}$ & $\begin{array}{l}0.41 \\
(1.1)\end{array}$ \\
\hline $\begin{array}{r}\text { 8. Rural } 2 \\
\text { Wife's Background }\end{array}$ & $\begin{array}{r}-0.08 \\
(0.2)\end{array}$ & $\begin{array}{r}0.19 \\
(0.4)\end{array}$ & $\begin{array}{l}0.25 \\
(0.6)\end{array}$ \\
\hline 9. Born in village & $\begin{array}{r}0.18 \\
(0.8)\end{array}$ & $\begin{array}{l}0.02 \\
(0.1)\end{array}$ & $\begin{array}{c}0.01 \\
(0.05)\end{array}$ \\
\hline 10. Lived in town & 0.07 & 0.24 & 0.23 \\
\hline $\begin{array}{l}\text { 11. Current age } \\
\text { Other Variables }\end{array}$ & $\begin{array}{l}(0.2) \\
0.05 \\
(2.4)\end{array}$ & $\begin{array}{l}(0.7) \\
0.05 \\
(2.1)\end{array}$ & $\begin{array}{l}(0.7) \\
0.06 \\
(2.5)\end{array}$ \\
\hline $\begin{array}{l}\text { 12. Mortality } \\
\text { 13. Age married }\end{array}$ & $\begin{array}{l}2.74 \\
(6.6)\end{array}$ & $\begin{array}{r}2.76 \\
(6.5)\end{array}$ & $\begin{array}{c}2.56 \\
(6.1) \\
-0.16\end{array}$ \\
\hline $\begin{array}{l}\text { 14. Intercept } \\
\mathrm{R}^{2} \\
\mathrm{~F}\end{array}$ & $\begin{array}{l}3.31 \\
0.10 \\
7.6\end{array}$ & $\begin{array}{l}3.28 \\
0.10 \\
6.7\end{array}$ & $\begin{array}{l}5.59 \\
0.14 \\
9.2\end{array}$ \\
\hline
\end{tabular}

2See note, Table 2 .
bt-Ratios in parentheses. amenoria, and a host of other "intermediate fertility" variables. This theory states that variations in fertility in noncontracepting populations are due to factors not directly related to couples' desires for children, but are, rather, the unintended consequences of decisions made in other areas of family behaviour.

The second theory is based on a fairly straightforward application of consumer demand theory to explain variations in the number of children couples have. Under this theory, costs of having and raising children, benefits that flow from children to parents, and resources available to couples are postulated to explain a significant proportion of the systematic component of variation in numbers of children among families.

To explore which of these theories better fits the facts in Pakistan, I concentrate on one particular relationship, the negative correlation between a wife's education and a number of children that she has. Both supply and demand theories provide explanations for that negative relationship, the first through a correlation between female education, age at marriage, and contraceptive use, and the second through a correlation between female education and the cost of having and rearing children. To measure the relative importance of these competing explanations, I first control for the major supply considerations using multivariate regression techniques. What remains is taken to be the effect of female education on fertility which arises from the demand side of the fertility equation, and this effect remains strongly negative even after supply considerations are removed from the data.

Although flawed by certain methodological problems, the empirical investigation carried out in this paper points quite clearly toward the conclusion that demand models of fertility are as effective in explaining variations in children ever born in "natural fertility" populations as they are in contracepting populations. ${ }^{13}$ If this conclusion is supported by additional research that rules out simultaneity as an explanation for the statistical results presented in Table 3, then important implications for public policy emerge: Population programmes that attempt to reduce fertility in Pakistan only by improving contraceptive availability and supply are unlikely to reduce fertility to acceptable levels; couple's desires for children must also change and by substantial amounts.
${ }^{13}$ This conclusion does not deny the importance of the relationship between female education and contraception, but it does suggest that increases in wife's schooling is a necessary, but not a sufficient, condition for increasing in contraceptive use. 


\section{Variable Definitions}

Wealth Variables

Husband's education

Electricity in house

Modern house type

Traditional house type

Price Variables

Wife's education

Rural 1

Rural 2

Wife's Background Variables Born village

0: Cannot read or write

1: Can read, not write

2: Can read, write, grades 0,1

3: Can read, write, grades 2-5

4: Can read, write, grades 6-9

5: Can read, write, education, other

Equals 1 if house has electricity; 0 otherwise.

Equals 1 if house type is pucca (modern construction); 0 otherwise.

Equals 1 if house type is katcha (traditional construction); 0 otherwise.

[housing comparison group: all other house types-mud, tin hut, etc.]

See husband's education.

Equals 1 for rural residents who visit towns frequently or occasionally, 0 otherwise.

Equals 1 for rural residents who seldom or never visit towns; 0 otherwise.

[rural comparison group: urban dwellers]

Equals 1 if wife born in a village; 0 otherwise.

Lived in town

Current age

Other Variables

Mortality

Equals 1 if wife ever lived in a town for more than six months; 0 otherwise.

Wife's age at time of survey.

\section{REFERENCES}

1. Becker, Gary S. "An Economic Analysis of Fertility." In Demographic and Economic Change in Developed Countries. Universities National Bureau Conference Series No. 11. Princeton, N.J.: Princeton University Press. 1960.

2. - and Nigel Tomes. "Child Endowments and the Quantity and Quality of Children." Journal of Political Economy. Vol. 84, No. 4. March/April 1973.

3. Ben-Porath, Yoram. "Economic Analysis of Fertility in Israel." In T.W. Schultz, (ed.): Economics of the Family. NBER. Chicago and London: University of Chicago Press. 1974.

4. De Tray, Dennis. "Child Quality and the Demand for Children." In T.W. Schultz, (ed.): Economics of the Family. NBER. Chicago and London: University of Chicago Press. 1974.

5. - "Age at Marriage and Fertility: A Policy Review." The Pakistan Development Review. Vol. XVI, No. 1. Spring 1977.

6. ___ "Child Schooling and Family Size: An Economic Analysis." R-2301/NICHD. The Rand Corporation, Santa Monica, California. 1978.

7. Easterlin, Richard A.; Michael A. Pollak and Michael L. Wachter. "Toward a More General Economic Model of Fertility Determination: Endogenous Preferences and Natural Fertility." Paper prepared for an NBER Conference on Population Change in Less Developed Countries. 1976.

8. Henry, Louis. "Theoretical Basis of Measures of Natural Fertility." In M.C. Sheps and Laspierre Adamcyk (eds.): On The Measurement of Human Fertility-Selected Writings of Louis Henry. New York: Elseevier Publishing Co. 1972.

9. Khan, Zahira Saleem. "Returns to Female Schooling in Rawalpindi." Study in progress. Pakistan Institute of Development Economics. 1978.

10. Leibenstein, Harvey. "An Interpretation of the Economic Theory of Fertility." Journal of Economic Literature. Vol. XII, No. 2. June 1974. pp. 457-79.

11. ․ "Beyond Economic Man: Politics and the Population Problem." Population and Development Review. Vol. 3, No. 3. September 1977. pp. 183-200.

Ratio of child deaths to children ever born.

12. Michael, Robert. "Education and the Derived Demand for Children." In T.W. Schultz (ed.): Economics of the Family. NBER. Chicago and London: The University of Chicago Press. 1974.

13. Schultz, T. Paul. "Fertility Determinants: A Theory, Evidence, and An Application to Policy Evaluation." R-1016. The Rand Corporation, Santa Monica, California. 1974.

14. Willis, Robert J. "Economic Theory of Fertility Behavior." In T.W. Schultz (ed.): Economics of the Family. NBER. Chicago and London: The University of Chicago Press. 1974. 